\title{
Prevalence of dysmenorrhea in female students in a Chinese university: a prospective study
}

\author{
Hong-Gui Zhou ${ }^{1}$, Zheng-Wei Yang ${ }^{2}$, Students Group ${ }^{3}$ \\ ${ }^{1}$ Department of Gynecology and Obstetrics, the Affiliated Hospital of North Sichuan Medical College, Nanchong, China \\ ${ }^{2}$ Morphometric Research Laboratory, North Sichuan Medical College, Nanchong, China; zwyang@nsmc.edu.cn \\ ${ }^{3}$ Undergraduate students of North Sichuan Medical College, including Hong-Yu Chen, Hua-Qiu Chen, Li Chen, Ling Chen, Yu-Zi \\ Chen, Xia Chuan, Chun-Ni Deng, Li-Tao Fan, Na Fu, Cui-Mei Gan, Yan Gou, Jing Guo, Li-Ya He, Ya-Jie Hou, Qin Hu, Xiao-Juan \\ Huang, Lin-Ling Li, Xiao-Zuo Li, Xiao-Lan Lin, Chun-Xia Liu, Dan Liu, Xu Liu, Yin-Hua Peng, Jun Qian, Xue-Fang Ren, Wen \\ Tang, Hai-Bo Wang, Hui-Min Wang, Qi Wang, Qian-Qian Wang, Yao Xie, Yao-Yao Yu, Ling Zeng, Huan Zhang, Qiong-Yue Zhang, \\ Jian-Ping Zhao, Chang-Feng Zhou, Xue-Yu Zhou, Yang-Lin Zhou (in surnames’alphabetical order).
}

Received 28 December 2009; revised 20 January 2010; accepted 25 January 2010.

\begin{abstract}
This study aimed to investigate the prevalence of dysmenorrhea in a prospective approach. Menstruation-related diary data were obtained from 2640 female college students in North Sichuan Medical College; dysmenorrhea and related factors were analyzed. Dysmenorrhea occurred in $56.4 \%$ of students; $6.5 \%$ of dysmenorrheal students suffered from "hard to bear" (unbearable) menstrual pain, and $6.5 \%$ had pre-menstrual dysmenorrhea. The more severe dysmenorrhea was, the longer dysmenorrhea lasted, and the longer the duration of menstruation and the larger the amount of menstrual blood flow appeared to be. Dysmenorrhea occurred on $37 \%$ of the menstrual dates on average and was unrelated to irregularity of menstrual cycles. The percentages of students taking medicine with mild, moderate and unbearable dysmenorrhea were $4.0 \%$, $13.3 \%$ and $23.7 \%$, respectively.
\end{abstract}

Keywords: College Students; Dysmenorrhea; Prospective Study

\section{INTRODUCTION}

Many investigations have been undertaken to determine the prevalence of dysmenorrhea (painful menstruation), the commonest (not necessarily the most serious) complaint associated with menstruation [1]. The prevalence varied widely between investigations. As published in English, for example, the prevalence (rate of occurrence) of dysmenorrhea ranged from $72.3 \%$ to $89.5 \%$ in Nigerian and Turkey university students [2,3], and from
$59.7 \%$ to $85.0 \%$ in adolescent girls or young women [4-8]. In China, university/college students were the main subjects investigated and the prevalence of dysmenorrhea (reported in Chinese journals) varied from $31.5 \%-41.9 \%$ [9-13] to 57.1\%-79.4\% [14-18]. Previous investigations were, however, retrospective ones by means of questionnaires. In some investigations it was stated that the dysmenorrheal data were about the menstrual pain that occurred every month or frequently [11] or during the past 3 months [8], and in most other investigations it was unknown whether the dysmenorrhea was defined as the menstrual pain that occurred during the past 1 or several weeks, or during the last 1 or several periods. This would cloud the prevalence data. This current investigation was therefore undertaken, by adopting a prospective approach (by means of diary), to study the prevalence of dysmenorrhea in female students in a Chinese university.

\section{METHODS}

The students investigated were Grades 2004-2007 female undergraduate students residing on the campus of North Sichuan Medical College. 37 of them and 2 male undergraduates constituting the Students Group were recruited as volunteers to assist in the investigation.

A diary table was distributed to students on October 21, 2007. They were requested to keep record of their menstrual dates, amount of menstrual blood flow (too little, moderate or too much), dysmenorrhea (lower abdominal pain associated with menstruation) and medications taken for menstrual disorder. The completed diary tables were collected by January 18, 2008 (the end of the semester).

2876 students participated in the study. 230 of them wrote on the diary that they forgot to fill in part of the menstrual data and 6 students had no menstruation dur- 
ing investigation. These students being excluded, the analysis in this study was based on data from the other 2640 students. These students were, on October 2007 at the beginning of investigation, aged $20.3 \pm 1.3$ (SD) full years (range, 16-26; median, 20; 5th and 95th percentiles, 18 and 22).

The first menstruation during the period of investigation was used for the analysis of dysmenorrhea (including pre-menstrual dysmenorrhea), which was divided into 3 levels: mild (not affecting life or work, without worry or concern), moderate and unbearable (the original Chinese words means "hard to bear" literally). When a student had 1 or more days of unbearable pain, she was classified into the group of unbearable dysmenorrhea. When she had no unbearable pain but had 1 or more days of moderate pain, she was grouped into moderate dysmenorrhea. Mild dysmenorrheal students had mild but no unbearable or moderate pain.

\section{RESULTS}

The prevalence of dysmenorrhea was 56.4\%. 64.7\% of the dysmenorrheal students had mild dysmenorrhea, 28.8\% moderate dysmenorrhea and 6.5\% unbearable dysmenorrhea (Table 1). 3.67\% of the 2640 students had pre-menstrual dysmenorrhea and $1.10 \%$ had only pre-menstrual pain without pain during menstruation. An average of $8.0 \%$ of dysmenorrheal students took medicine; the percentages of students taking medicine with mild, moderate and unbearable dysmenorrhea were $4.0 \%$, $13.3 \%$ and $23.7 \%$, respectively.

The average duration of menstruation was $3.79 \pm 1.22$ days (median, 4 days); 261 (9.89\%) students had abnormal menstrual cycles [19] $>40$ days or $<18$ days. Compared to non-dysmenorrheal students, dysmenorrheal students were slightly older in age, had slightly longer menstruation, and had more days on which they felt there was more menstrual blood loss (Table 1). The number of dates with dysmenorrhea during menstruation increased significantly with the increase of dysmenorrheal levels (Table 1). In dysmenorrheal students, the mean number of menstrual dates in the menstrual period was $4.84 \pm 1.24$ and dysmenorrhea occurred on $37.1 \% \pm$ $22.8 \%$ of the menstrual dates. [Note, for each period of menstruation, the number of menstrual dates is 1 larger than the duration (days) of menstruation.] There was no significant difference in the percentage of students with abnormal menstrual cycles between groups of students without and with dysmenorrhea (Table 1).

\section{DISCUSSION}

This is a large prospective investigation undertaken to study the prevalence of dysmenorrhea. It demonstrated that the prevalence of dysmenorrhea in female college students in a Chinese university was 56.4\%. It also demonstrated for the first time that 1) dysmenorrhea occurred on $<40 \%$ of the menstrual dates on average, and 2) the more severe dysmenorrhea was, the longer dysmenorrhea lasted: the mean number of dysmenorrheal dates during menstruation in unbearable dysmenorrheal students was $>60 \%$ larger than that in mild dysmenorrheal students (Table 1). It was previously reported that the severity of dysmenorrhea increased with increasing duration of menstruation or amount of menstrual flow [5-6]. As also shown in the current study, the prevalence or severity of dysmenorrhea was unrelated to irregularity of menstrual cycles (Table 1).

The prevalence of dysmenorrhea in college students, a relatively convenient sample to study, was reported with wide variation in previous studies (see the Introduction). A recent (data collected in June 2006) large $(n=15392)$ study in 7 universities for minority nationalities reported, for example, an overall prevalence of $65.6 \%$ among the second and third year college students on campus, with no significant differences between major nationalities; however, the prevalence was $84.8 \%$ in 1 university ( $\mathrm{n}=$ 2097) [18]. Strictly speaking, our result of $56.4 \%$ obtained prospectively was not comparable to previous (retrospective) results. A dysmenorrheal woman was defined in this study as suffering from dysmenorrhea in one (the first) menstrual period during investigation. So the dysmenorrheal prevalence obtained in this study reflected the prevalence among the women at certain time point. If a woman was defined as dysmenorrheal even if dysmenorrhea occurred in only one of her past 10 or 20 periods, each woman would likely be dysmenorrheal, i.e. the prevalence would be approximating to $100 \%$. The prevalence (85\%) of dysmenorrhea occurring during the past 3 months among high school students [8], for example, would certainly overestimate the prevalence at certain time point. Previous studies were usually retrospective, associated with recall bias, and in most previous studies it was unknown how the dysmenorrhea was defined (see the Introduction).

Severity of dysmenorrhea is a subjective feeling, which may be variable between groups of women. Severe (in comparison with mild or moderate) dysmenorrhea was reported in $10 \%-42 \%$ of Western dysmenorrheal women [4-6,8] while the percentage was $6.5 \%$ $6.7 \%$ in Chinese dysmenorrheal college students $[9,15]$. Menstruation may be likened to an internal bleeding, wound or trauma and would naturally cause some concern, painful or uncomfortable feeling, to which women would get accustomed one way or another. It is therefore those who feel "hard to bear" (unbearable) that we should pay special attention to. As estimated in the present study, this subgroup of people with unbearable 
Table 1. Main results (mean \pm SD) for college students without dysmenorrhea and with mild, moderate or unbearable dysmenorrhea.

\begin{tabular}{|c|c|c|c|c|}
\hline & $\begin{array}{l}\text { Without } \\
(\mathrm{n}=1150)\end{array}$ & $\begin{array}{c}\text { Mild } \\
(\mathrm{n}=964)\end{array}$ & $\begin{array}{l}\text { Moderate } \\
(\mathrm{n}=429)\end{array}$ & $\begin{array}{c}\text { Unbearable } \\
(\mathrm{n}=97)\end{array}$ \\
\hline Age (full years) * & $20.2 \pm 1.3^{\mathrm{abc}}$ & $20.4 \pm 1.4$ & $20.5 \pm 1.3$ & $20.7 \pm 1.3$ \\
\hline Duration of menstruation (days) * & $3.72 \pm 1.20$ & $3.81 \pm 1.20$ & $3.91 \pm 1.30$ & $3.90 \pm 1.33$ \\
\hline $\begin{array}{l}\text { No. of dates with dysmenorrhea during men- } \\
\text { struation* }\end{array}$ & - & $1.49 \pm 0.91^{\text {bc }}$ & $2.07 \pm 1.06^{c}$ & $2.43 \pm 1.31$ \\
\hline $\begin{array}{l}\text { No. of dates with little blood flow during men- } \\
\text { struation* }\end{array}$ & $1.50 \pm 1.49$ & $1.54 \pm 1.41$ & $1.70 \pm 1.48$ & $1.69 \pm 1.52$ \\
\hline $\begin{array}{l}\text { No. of dates with moderate blood flow during } \\
\text { menstruation * }\end{array}$ & $2.99 \pm 1.71$ & $2.97 \pm 1.54$ & $2.81 \pm 1.60$ & $2.64 \pm 1.77$ \\
\hline $\begin{array}{l}\text { No. of dates with much blood flow during } \\
\text { menstruation* }\end{array}$ & $0.23 \pm 0.61^{\mathrm{abc}}$ & $0.29 \pm 0.60^{\mathrm{bc}}$ & $0.40 \pm 0.67$ & $0.57 \pm 0.93$ \\
\hline $\begin{array}{l}\text { Percentage of students with abnormal men- } \\
\text { strual cycle } \#\end{array}$ & $10.17 \%$ & $9.02 \%$ & $11.19 \%$ & $9.28 \%$ \\
\hline
\end{tabular}

*Data were significantly different $(P \leq 0.05)$ between the 4 groups or the 3 dysmenorrheal groups (Kruskal-Wallis one way analysis of variance on ranks); significantly different $(P \leq 0.05)$ from the group of mild ${ }^{\mathbf{a}}$, moderate ${ }^{\mathrm{b}}$ or unbearable ${ }^{\mathrm{c}}$ dysmenorrhea (Dunn's method for multiple comparison). \#Abnormal menstrual cycle: $\leq 17$ or $\geq 41$ days; there was no significant difference between the percentages ( $\chi^{2}$ test: $\left.P>0.50\right)$.

dysmenorrhea accounted for $6.5 \%$ of the dysmenorrheal students, similar to the "severe" (treatment was needed and school study could not be continued) results (6.5\%-6.7\%) previously reported in Chinese college students $[9,15]$. Even with unbearable dysmenorrhea, the students just seemed to bear it without taking medicine-less than 25\% of them took medicine. Menstruation-related health education programs are therefore needed on campus to promote the menstrual health of students.

The percentage of dysmenorrheal students taking medicine for dysmenorrhea was previously reported to be 50\%-58\% among Turkey and British undergraduate students [3,20], 52\%-58\% among American and Australian high school students [7,8], more than 43.8\% among Chinese undergraduate students [18], and $33 \%-38 \%$ among young Sweden women $[5,6]$. These results are much higher than our result $(8.0 \%)$. This may be indicative of wide variation in the attitude of medicine taking or in the tolerance to pain between groups (people) or regions (places), and/or indicative of the "cumulative effects" in retrospective studies, like the overestimation of dysmenorrheal prevalence as described above.

Dysmenorrhea in the present study is essentially primary dysmenorrhea [1] since no students in this investigation reported underlying pelvic pathology during study. In talking with some dysmenorrheal students during study, we identified a couple of students whose dysmenorrhea might be secondary, but this was not confirmed because they did not seek further consultation or examination.

\section{ACKNOWLEDGMENTS}

This study was supported by grants from the Nanchong Bureau of Science and Technology (N2007-SF010) and the Sichuan Department of Education (08ZA110).

\section{REFERENCES}

[1] Rees, M.C.P. (2007) Menstrual problems: Menorrhagia and primary dysmenorrhagia. In Edmonds, K. Ed., Dewhurst's Textbook of Obstetrics and Gynaecology. Blackwell Publishing, 399-407.

[2] Thomas, K.D., Okonofua, F.E. and Chiboka, O. (1990) A study of the menstrual patterns of adolescents in Ile-Ife, Nigeria. International Journal of Gynecology \& Obstetrics, 33, 31-34.

[3] Cakir, M., Mungan, I., Karakas, T., Girisken, I. and Okten, A. (2007) Menstrual pattern and common menstrual disorders among university students in Turkey. Pediatrics International, 49, 938-942.

[4] Klein, J.R. and Litt, I.F. (1981) Epidemiology of adolescent dysmenorrhea. Pediatrics, 68, 661-664.

[5] Andersch, B. and Milsom, I. (1982) An epidemiologic study of young women with dysmenorrhea. American Journal of Obstetrics and Gynecology, 144, 655-660.

[6] Sundell, G., Milsom, I. and Andersch, B.(1990) Factors influencing the prevalence and severity of dysmenorrhoea in young women. British Journal of Obstetrics and Gynaecology, 97, 588-594.

[7] Hillen, T.I., Grbavac, S.L., Johnston, P.J., Straton, J.A. and Keogh, J.M. (1999). Primary dysmenorrhea in young Western Australian women: Prevalence, impact, and knowledge of treatment. Journal of Adolescent Health, 25, 40-45.

[8] Banikarim, C., Chacko, M.R. and Kelder, S.H. (2000) Prevalence and impact of dysmenorrhea on Hispanic female adolescents. Archives of Pediatrics \& Adolescent Medicine, 154, 1226-1229.

[9] Guo, L.Y., Shao, L.X., Wang, B.Q. and Tan, M.T. (1994) Investigation of dysmenorrhea in 1341 female college students. Journal of Convalescence and Rehabilitation, 9, 31-33 (in Chinese).

[10] Ma, Y.N. (1996) Study of sports activity and dysmenorrheal prevalence during menstruation in female college students. Zhejiang Sport Science, 18, 52-55 (in Chinese).

[11] Hao, G.R. and Liu, D. (2000) Analysis of dysmenorrhea of 634 university schoolgirls. Journal of Taishan Medical College, 21, 235-236 (in Chinese). 
[12] Xu, M. and Geng, T.J. (2002) Menstrual investigation of 435 female college students. Chinese Journal of School Doctor, 16, 43 (in Chinese).

[13] Zhan, Q.L. (2003) Menstrual investigation of 506 female college students. Chinese Primary Health Care, 17, 46 (in Chinese).

[14] Wang, G.H., Chen, W.Y. and Wang, X.J. (1997). Investigation of the prevalence and related factors of dysmenorrhea in female college students. Chinese Journal of Preventive Medicine, 31, 253 (in Chinese).

[15] Huang, B., Rang, W.Q. and Long, Y. (2004) Survey and analysis on menstrual status of female college students in Hengyang. Practical Preventive Medicine, 11, 34-35 (in Chinese).

[16] Wei, Y.P., Wu, M., Ling, Y. and Wang, Z.Z. (2006) Investigation of dysmenorrhea in female college students. Jiangsu Journal of Traditional Chinese Medicine, 27, 26-27 (in Chinese).
[17] Wang, B.G., Chen, S.D., Zhou, W.P. and Wang, G.Q. (2008) Study on the menstrual periods and health care of female college students in Guangzhou. Chinese Journal of School Doctor, 22, 162-163 (in Chinese).

[18] Yu, Q.H., Zhu, D., Yun, M.Y. and Kang, X.P. (2008) Investigation of dysmenorrhea status and intervention of Chinese medicine of female undergraduate students of each nationality. Chinese Journal of Family Planning, 16, 478-480 (in Chinese).

[19] Harlow, S.D., Lin, X. and Ho, M.J. 2000. Analysis of menstrual diary data across the reproductive life span applicability of the bipartite model approach and the importance of within-woman variance. Journal of Clinical Epidemiology, 53, 722-733.

[20] Hewison, A. and van den Akker, O.B. (1996) Dysmenorrhoea, menstrual attitude and GP consultation. British Journal of Nursing, 5, 480-484. 